\title{
FREQUENCY OF VITAMIN D DEFICIENCY IN PATIENTS PRESENTING WITH FIBROMYALGIA
}

\author{
Samina Rashid, Khuram Haq Nawaz, Amer Fakhr, Hammad Ather, Farzana Hakeem*, Rizwan Yousaf** \\ Pak Emirates Military Hospital/National University of Medical Sciences (NUMS) Rawalpindi Pakistan, *Foundation University, Islamabad Pakistan, \\ ${ }^{* *}$ Combined Military Hospital Okara/National University of Medical Sciences (NUMS) Pakistan
}

\begin{abstract}
Objective: To determine frequency of vitamin D deficiency in patients presenting with fibromyalgia and its association with various factors.

Study Design: Cross sectional study.

Place and Duration of Study: Medicine department, Pak Emirates Military Hospital Rawalpindi, from Sep 2018 to Feb 2019. Methodology: Ninety patients of fibromyalgia were included in the study. Diagnosis of fibromyalgia was made by the consultant rheumatologist on the basis of American College of Rheumatology Criteria needed for fibromyalgia diagnosis and classification. Vitamin D levels $<20 \mathrm{ng} / \mathrm{ml}$ were considered as deficient. Age, education, marital status, menstrual abnormallities and body mass index were correlated with the presence of vitamin D deficiency among the patients suffering from fibromyalgia.

Results: Out of 90 patients of fibromyalgia, 57 (63.3\%) showed the presence of vitamin D deficiency while $33(36.7 \%)$ had no deficiency of vitamin D. Among the study participants $88(97.8 \%)$ patients were females and only $2(2.2 \%)$ patients were males. Mean age of the patients was $39.4 \pm 3.365$ years. After applying the binary logistic regression, we found that presence of menstrual abnormalities and high body mass index had significant association with the presence of vitamin D deficiency among the patients of fibromyalgia ( $p$-value $<0.05)$.

Conclusion: Vitamin D deficiency emerged as a common finding among the patients of fibromyalgia in a teaching hospital of Pakistan. Vitamin D deficiency should be screened at the rheumatology clinics and special attention should be paid to the patients who are overweight or obese and female patients with the menstrual abnormalities.
\end{abstract}

Keywords: Fibromyalgia, Socio-demographic factors, Vitamin D.

How to Cite This Article: Rashid S, Nawaz KH, Fakhr A, Ather H, Hakeem F, Yousaf R. Frequency of Vitamin D Deficiency in Patients Presenting with Fibromyalgia. Pak Armed Forces Med J 2021; 71(5): 1544-1547. doi: https://doi.org/10.51253/pafmj.v71i5.2973

\footnotetext{
This is an Open Access article distributed under the terms of the Creative Commons Attribution License (https://creativecommons.org/licenses/by-nc/4.0/), which permits unrestricted use, distribution, and reproduction in any medium, provided the original work is properly cited.
}

\section{INTRODUCTION}

A common condition often missed by the clinicians among the patients presenting with different aches and pains has been fibromyalgia. A high percentage of patients $(40-80 \%)$ with this disorder often remain undiagnosed for quite a long time. ${ }^{1}$ Fibromyalgia is one of the rheumatologic conditions which is prevalent $(2-6 \%)$ in all parts of the world including Pakistan. 1,2 It has been associated with many biochemical abnormalities including elevated CSF kynurenine, low serum serotonin, low serum vitamin $\mathrm{D}$ and low red cell NADP, NADH, and ATP. .,4

Vitamin D deficiency is a common problem especially among the females of developing countries including Pakistan. 5,6 Many medical, neurological and psychiatric illnesses have been linked with vitamin D deficiency. Endocrinopathies, rheumatologic diseases, kidney diseases and mental health problems are some of

Correspondence: Dr Samina Rashid, Department of Medicine, Pak Emirates Military Hospital, Rawalpindi Pakistan

Received: 15 Jun 2019; revision received: 02 Apr 2020; accepted: 20 Apr 2020 the diseases linked with vitamin D deficiency among the individuals. 7,8

Vitamin D deficiency among the patients suffering from both fibromyalgia and other rheumatologic diseases has been frequently documented in the scientific literature. Makrrani et al. concluded that vitamin D deficiency was more prevalent in fibromyalgia patients as compared to the controls. ${ }^{9}$ Majority of the patients with fibromyalgia had vitamin D deficiency in a study done in KSA. ${ }^{10}$

This aspect of fibromyalgia and associated vitamin D deficiency has not been studied much in our region. This study was planned with the aim to assess the frequency of vitamin D deficiency among the patients of fibromyalgia and analyze the associated sociodemographic factors linked with the presence of vitamin D deficiency anemia among these patients.

\section{METHODOLOGY}

This cross sectional study was conducted at the General Medicine Department of Pak Emirates Military Hospital, Rawalpindi, between September 
2018 to February 2019. Non-probability consecutive sampling technique was used to recruit the samples for the study. Sample size was calculated by using the WHO sample size calculator and keeping the population prevalence proportion of $94 \% .{ }^{11}$

Inclusion Criteria: All the patients of fibromyalgia diagnosed by a consultant rheumatologist on American College of Rheumatologist Criteria. ${ }^{12}$ American College of Rheumatology Criteria needed for fibromyalgia diagnosis and classification was used by the consultant rheumatologist to make the final diagnosis of fibromyalgia. ${ }^{13,14}$

Exclusion Criteria: The patients more than 60 years of age, those who did not give their consent, those with a past or current history of any chronic physical or psychiatric illness, current history of substance use, patients who were pregnant or breast-feeding, had thyroid or parathyroid abnormalities, had osteo-malacia or could not read the questionnaire.

All ethical aspects were catered for the study including the formal ethical approval and formal consent from the patients after providing them all the information regarding the study and mentioning them their right to withdraw at any time from the study if they did not feel comfortable being part of the study. The concentration of vitamin D3 in serum was measured by electrochemiluminescence immunoassay on a Roche Elecsys (Roche Diagnosis, Penzberg, Germany). ${ }^{15,16}$ It is a competitive assay in which the binding protein of vitamin D3 is inactivated during incubation. The assay employs a polyclonal antibody directed against vitamin D3. This method can measure the concentration of vitamin D3 in the range of $4-100 \mathrm{ng} / \mathrm{mL}$ (10-250 nmol/L). ${ }^{17}$ Socio demographic variables of the study participants were also collected. Variables in the study included age, marital status, education, menstrual abnormalities and BMI. WHO classification of body mass index was used to group the patients according to their weight and height ratio. ${ }^{14}$ Researchers designed the proforma for the study variables before the start of the study and all the data before the start of study and all the data was entered into the proforma before being put into the required software.

Interpretation of vitamin $\mathrm{D}$ levels was done as; normal $>30 \mathrm{ng} / \mathrm{ml}$; deficiency levels $<20 \mathrm{ng} / \mathrm{dl}^{.17}$

Descriptive statistics were used in the study to describe the study variables using SPSS-23. Presence and absence of vitamin D deficiency was mentioned by using the percentage and frequency. Chi-square was the statistical test applied initially to establish any association between the variables and vitamin D deficiency. Differences between groups were considered significant if $p$-values were $\leq 0.05$.

\section{RESULTS}

On hundred and three patients of fibromyalgia were approached to participate in the study. Thirteen out of these either were fulfilling the inclusion/ exclusion criteria or did not consent or withdrew consent later on, leaving 90 participants who had completion of the laboratory tests and got the reports. Mean age of the patients was $39.4 \pm 3.365$ years. Out of 90,57 $(63.3 \%)$ showed vitamin D deficiency, while 33 (36\%) had no deficiency of vitamin D. Table shows the distribution of the patients with respect to the presence of vitamin D deficiency. Presence of menstrual abnormalities among the females and high body mass index had significant association with vitamin D deficiency $p=0.010$.

Table: Characteristics of the study group and their vitamin D levels.

\begin{tabular}{|c|c|c|c|}
\hline $\begin{array}{l}\text { Socio Demographic } \\
\text { Factors } \\
\text { Total }\end{array}$ & $\begin{array}{c}\text { No vitamin } \\
\text { D deficiency } \\
\text { n (\%) } \\
33(36.7) \\
\text { (ng/dl) }\end{array}$ & $\begin{array}{c}\text { Vitamin D } \\
\text { deficiency } \\
\text { n (\%) } \\
57(63.3) \\
\text { (ng/dl) } \\
\end{array}$ & $\begin{array}{c}p \text { - } \\
\text { value }\end{array}$ \\
\hline \multicolumn{4}{|l|}{ Age } \\
\hline $\begin{array}{l}\leq 40 \text { year } \\
>40 \text { years }\end{array}$ & $\begin{array}{c}29(87.9) \\
4(12.1) \\
\end{array}$ & $\begin{array}{l}45(78.9) \\
12(21.1)\end{array}$ & 0.274 \\
\hline \multicolumn{4}{|l|}{ Marital Status } \\
\hline $\begin{array}{l}\text { Married } \\
\text { Unmarried/widowed }\end{array}$ & $\begin{array}{l}14(42.4) \\
19(57.6) \\
\end{array}$ & $\begin{array}{l}31(54.4) \\
26(45.6) \\
\end{array}$ & 0.273 \\
\hline \multicolumn{4}{|l|}{ Education } \\
\hline $\begin{array}{l}<10 \text { years } \\
\geq 10 \text { years }\end{array}$ & $\begin{array}{l}11(33.3) \\
22(66.7)\end{array}$ & $\begin{array}{l}21(36.8) \\
36(63.2)\end{array}$ & 0.737 \\
\hline \multicolumn{4}{|l|}{ Menstrual Abnormalities } \\
\hline $\begin{array}{l}\text { No } \\
\text { Yes }\end{array}$ & $\begin{array}{l}20(60.6) \\
13(39.4)\end{array}$ & $\begin{array}{l}24(42.1) \\
33(57.9) \\
\end{array}$ & 0.090 \\
\hline \multicolumn{4}{|l|}{ Body Mass Index } \\
\hline $\begin{array}{l}\text { Normal } \\
\text { Overweight or obese }\end{array}$ & $\begin{array}{c}28(84.8) \\
5(15.2) \\
\end{array}$ & $\begin{array}{l}34(59.6) \\
23(40.4) \\
\end{array}$ & 0.010 \\
\hline
\end{tabular}

\section{DISCUSSION}

This study is instrumental in understanding the relationship of a metabolic abnormality with a disease whose basis is not very clear. Using simple laboratory investigations, around 57 (63\%) of the patients enrolled in the study showed the presence of vitamin D deficiency. A local study done in the past by Bhatty et al. Showed high prevalence of vitamin D deficiency among the females suffering from fibromyalgia. ${ }^{11}$ These two conditions might be sharing the etiological basis or may have a bimodal relationship as administration of vitamin D not only alleviates the symptoms 
of fibromyalgia but also improves the overall quality of life of the individual. ${ }^{12}$

The mechanism by which fibromyalgia and vitamin D deficiency may be interlinked is complex and multidimensional. Neurotransmitter model is most often used to explain this relationship. Fibromyalgia is thought to be because of alteration in neuro-chemicals in brain amplifying the peripheral pain sensations. Vitamin D may enhance these sensations as it has been studied that they have a role in etiology and maintenance of chronic painful conditions. ${ }^{4,13}$

Presence of vitamin D deficiency among the patients suffering from fibromyalgia and similar rheumatologic conditions has been influenced by various factors. Some of these include covering the body including the face, increasing age, wide spread pain index and high body mass index. ${ }^{11,14}$

Use of veil (covering their body including the face), increasing age, wide spread pain index and high body mass index are few parameters linked with presence of vitamin D deficiency in studies done by Bhatty et al, and Nikiphorou et al.11,14 These factors may affect the vitamin D levels either by direct physiological cause or indirectly by other mechanisms. Bimodal relationship of vitamin D deficiency and fibromyalgia is also an interesting and emerging phenomenon. ${ }^{3}$

Vitamin D deficiency is a problem with more than one dimension including physical, nutritional and physiological dimensions. Fibromyalgia or its treatment should be understood by taking into account all these dimensions. Even etiological factors for fibromyalgia may include vitamin $\mathrm{D}$ deficiency. When the symptomatology of this illness start, patient is usually unable to comprehend the vague symptoms. These symptoms may be due to vitamin $\mathrm{D}$ deficiency which sometimes causes delay in diagnosis and treatment of this aspect of fibromyalgia. Normal vitamin D levels are required for good overall quality of life especially among the patients with fibromyalgia and other rheumatologic disorders. ${ }^{12}$ Timely diagnosis by the treating clinician may be related to better results in managing this chronic painful condition. . $^{12,17}$

Age was not related to the presence of vitamin D deficiency in our study. Vitamin D deficiency among the patients of fibromyalgia was not statistically related to increasing age in studies done across the world. Studies of Bhatty et al and Maafi et al, are important in this regard, which could not establish any relationship of age with the presence of vitamin D deficiency.11,18 Reason might be narrow age range of our study population as we only included patients below the age of sixty. More studies are needed with wide age range and sophisticated study design to ascertain this association.

Presence of menstrual abnormalities was strongly related to the presence of vitamin D deficiency in our study on both chi-square and binary logistic regression ( $p$-value $<0.05)$. Past studies have also supported this association. ${ }^{19}$

Study of Matyjaszek-Matuszek et al is worth mentioning in this regard which came up with the finding that menstrual abnormalities have a strong relationship with presence of vitamin D deficiency. ${ }^{19}$ Menstural abnormalities include oligomenorrhea, menorrhagia, dysmenorrhea, abnormal uterine bleeding, premenstrual syndrome, premenstrual dysphoric disorder etc. Fibromyalgia, menstrual abnormalities and vitamin D levels may be interlinked and a positive feedback loop among these may worsen the condition of patients. Therefore, timely screening and a multi-disciplinary approach involving a gynecologist and a rheumatologist may prove beneficial for the patient.

Previous researches have highlighted the inverse relationship of body mass index with iron deficiency anemia. ${ }^{14,19}$ Nikiphorou et al. performed an interesting analysis which included BMI as an independent variable and they came up with the result that it has significant association with the presence of vitamin D deficiency. ${ }^{14}$ This was not the finding in our study. Sample from one center and strict inclusion criteria may be the reason of our finding. Studies with large sample size with wide range of age group may support this association.

\section{LIMITATIONS OF STUDY}

Limitation of the study include the confounding variables which were not studied, like the nutrition status and using of veil etc. They could be studied in future researches on this topic. For establishing the exact cause and effect relationship between vitamin D levels and fibromyalgia case control or cohort studies would be better options but they involve more time and resources. Using the results of our study as a baseline data researchers could plan more studies and generate better results.

\section{CONCLUSION}

Vitamin D deficiency emerged as a common finding among the patients of fibromyalgia in at a tertiary care hospital of Pakistan. Vitamin D deficiency should be screened at the rheumatology clinics and special attention should be paid to the patients who are overweight or obese and female patients with menstrual abnormalities.

Conflict of Interest: None. 


\section{Authors' Contribution}

SR: Original Idea \& Compilation, KHN: Original Idea \& Compilation, AF: Original Idea \& Compilation, HA: Data Collection \& Analysis, FH: Data Analysis, RY: Data Analysis \& Discussion.

\section{REFERENCES}

1. Walitt B, Nahin RL, Katz RS. The prevalence and characteristics of fibromyalgia in the 2012 national health interview survey. Cordero MD, ed. PLoS One 2015; 10(9): e0138024.

2. Rehman N, Rehman Y. Prevalence of fibromyalgia and chronic wide spread pain in Pakistani Population; Literature Review. Int J Curr Med Sci 2016; 6(12): 196-199.

3. Russel IJ. Biochemical abnormalities in fibromyalgia syndrome. J Musculoskelet Pain 2010; 2(3): 101-115.

4. Karras S, Rapti E. Vitamin D in fibromy-algia: a causative or confounding biological interplay. Nutrient 2016; 8(6): 343-348.

5. Sofi NY, Jain M, Kapil U, Seenu V, Ramakrishnan L, Yadav CP, et al. Status of serum vitamin D and calcium levels in women of reproductive age in national capital territory of India. Indian J Endocrinol Metabol 2017; 21(5): 731-733.

6. Lowe NM, Bhojani I. Special considerations for vitamin D in the south Asian population in the UK. Ther Adv Musculoskelet Dis 2017; 9(6): 137-144.

7. Bilge U, Kaşifoğlu T, Bilge NY, Balcığlu H, Sari YE, Kayhan M, et al. THU0478 Determination of comorbidities in fibromyalgia syndrome. Ann Rheum Dis 2017; 76(2): 387-392.

8. Clauw DJ. Fibromyalgia and related conditions. Mayo Clin Proc 2015; 90(5): 680-692.

9. Makrani AH, Afshari M, Ghajar M, Forooghi Z, Moosazadeh M. Vitamin D and fibromyalgia: a meta-analysis. Korean J Pain 2017; 30(4): 250-257.
10. Abokrysha NT. Vitamin D Deficiency in women with fibromyalgia in Saudi Arabia. Pain Med 2012; 13(3): 452-458.

11. Bhatty SA, Shaikh NA, Irfan M, Kashif SM, Vaswani AS, Sumbhai A, et al. Vitamin D deficiency in Fibromyalgia. J Pak Med Assoc 2010; 60(2): 949-951.

12. Dogru A, Balkarli A, Cobankara V, Tunc SE, Sahin M. Effects of Vitamin D therapy on quality of life in patients with fibromyalgia. Eurasian J Med 2017; 49(2): 113-117.

13. Bradley LA. Pathophysiology of fibromyalgia. J Med 2009; 122 (Suppl-12): S22.

14. Nikiphorou E, Uksila J, Sokka T. A cross-sectional study of vitamin D levels in a large cohort of patients with rheumatic diseases. Clin Rheumatol 2018; 37(3): 803-810.

15. Abbasi L, Haidri FR. Fibromyalgia complicating disease management in rheumatoid arthritis. J Coll Physicians Surg Pak 2014; 24(6): 424-27.

16. Sadat-Ali M, Al Essa ON, Alani FM, Al Omar HK, Ebrahim WY. Correlation of symptoms to serum vitamin D levels?. Clin Nutr ESPEN 2018; 24(1): 31-34.

17. Collado-Mateo D, Chen G, Garcia-Gordillo MA, Iezzi A, Adsuar JC, Olivares PR, et al. Fibromyalgia and quality of life: mapping the revised fibromyalgia impact questionnaire to the preferencebased instruments. Health Qual Life Outcome 2017; 15(1): 114118.

18. Maafi AA, Ghavidel-Parsa B, Haghdoost A, Aarabi Y, Hajiabbasi A, Shenavar Masooleh I, et al. Serum vitamin D status in iranian fibromyalgia patients: according to the symptom severity and illness invalidation. Korean J Pain 2016; 29(3): 172178.

19. Matyjaszek-Matuszek B, Lenart-Lipińska M, Woźniakowska E. Clinical implications of vitamin D deficiency. Przeglad Menopauzalny = Menopause Rev 2015; 14(2): 75-81. 